\title{
HUBUNGAN PENGETAHUAN PERAWAT TENTANG HEALTH ASSOCIATED INFECTIONS (HAIS) DENGAN PENERAPAN PRINSIP STERIL PEMASANGAN INFUS DI RUMAH SAKIT UMUM DAERAH H. SAHUDIN KUTACANE
}

\author{
Julwansa Saragih ${ }^{1}$, Riska Wani Eka Putri Perangin-Angin ${ }^{2}$ \\ ${ }^{1,2}$ Program Studi D3 Keperawatan AKPER KESDAM I/BB Pematangsiantar \\ Email: ${ }^{1}$ saragihjuan02@gmail.com, ${ }^{2}$ riskawani01@gmail.com
}

\begin{abstract}
ABSTRAK
Health Associaated Infections (HAIs) merupakan infeksi yang terjadi di rumah sakit salah satu infeksi yang terjadi yaitu infeksi aliran darah. Infeksi ini sering terjadi pada pasien yang terpasang infus untuk mencegah terjadinya infeksi perawat harus melakukan teknik septik-aseptik. Pengetahuan perawat tentang HAIs salah satu hal yang dapat mempengaruhi seseorang untuk menerapkan prinsip steril guna untuk mencegah terjadinya infeksi. Tujuan untuk mengetahui hubungan pengetahuan perawat tentang Health Associated Infections (HAIs) dengan penerapan prinsip steril pemasangan infus Di Rumah Sakit Umum Daerah H. Sahudin Kutacane Kabupaten Aceh Tenggara. Jenis penelitian yang digunakan deskriptif korelasi dengan desain cross sectional. Sampel penelitian ini yaitu perawat pelaksana di Rumah Sakit Umum Daerah H. Sahudin Kutacane Kabupaten Aceh Tenggara sebanyak 33 perawat. Teknik pengambilan sampel adalah accidental sampling. Hasil penelitian diperoleh pengetahuan perawat mayoritas cukup, penerapan prinsip steril mayoritas baik. Uji statistic chi-square diperoleh nilai p=0,016 hal ini menunjukan bahwa ada hubungan pengetahuan perawat tentang Health Associated Infections (HAIs) dengan penerapan prinsip steril pemasangan infus di Rumah Sakit Umum Daerah $H$. Sahudin Kutacane Kabupaten Aceh Tenggara. Saran bagi perawat agar lebih memperhatikan teknik septik-aseptik pada saat melakukan tindakan pemasangan infus.
\end{abstract}

Kata Kunci: Pengetahuan Perawat, Infeksi Nosokomial, Prinsip Steril Pemasangan Infus.

\section{ABSTRACT}

Health Associated Infections (HAIs) are infections that occur in hospitals. One of the infections that occurs is bloodstream infections. This infection often occurs in patients who are infusions to prevent infection, nurses must use aseptic-aseptic techniques. Nurses' knowledge about HAIs is one of the things that can influence a person to apply sterile principles in order to prevent infection. The purpose of this study was to determine the relationship between nurses' knowledge about Health Associated Infections (HAIs) and the application of the sterile principle of infusion at the H. Sahudin Kutacane Regional General Hospital, Southeast Aceh Regency. The type of research used is descriptive correlation with cross sectional design. The sample of this research is the implementing nurse at the Regional General Hospital H. Sahudin Kutacane, Southeast Aceh Regency as many as 33 nurses. The sampling technique is accidental sampling. The results of the study obtained that the majority of nurses' knowledge was sufficient, the application of the sterile principle was good. Chi-square statistical test obtained p value = 0.016, this shows that there is a relationship between nurses' knowledge about Health Associated Infections (HAIs) with the application of sterile principles of infusion at the H. Sahudin Kutacane Regional General Hospital, Southeast Aceh Regency. Suggestions for nurses to pay more attention to septic-aseptic techniques when performing infusions.

Keywords: Nurse Knowledge, Nosocomial Infections, Sterile Principles of Infusion Installation.

\section{PENDAHULUAN}

Penyakit infeksi masih menjadi salah satu masalah kesehatan di dunia, termasuk Indonesia. Infeksi dapat berasal dari masyarakat (community-acquired infection) atau dari lingkungan rumah sakit (HospitalAcquired Infection), dahulu dikenal dengan istilah infeksi nosokomial. Tindakan medis yang dilakukan oleh tenaga kesehatan untuk mengobati atau menyembuhkan pasien dapat menularkan penyakit menular kepada pasien lain atau bahkan kepada petugas kesehatan itu sendiri juga tidak mengikuti prosedur. Karena sumber penularannya tidak dapat ditentukan, maka istilah Hospital Acquired Infection kini diganti dengan istilah baru yaitu "Medical-Associated Infection" (HAI), yang memiliki arti lebih luas tidak hanya di 
rumah sakit, tetapi juga di bidang kesehatan lainnya. Fasilitas keperawatan tidak terbatas pada infeksi pasien, tetapi juga infeksi yang didapat oleh tenaga kesehatan. dan didapat pada saat melakukan perawatan pasien (Kemenkes RI, 2017).

Perkembangan Infeksi Rumah Sakit pada saat ini sangat meningkat mulai dari yang sifatnya mudah sampai dengan yang rumit, yang terdapat berbagai faktor. Terjadinya infeksi di rumah sakit dan upaya untuk dapat mengendalikan infeksi ditentukan oleh kewajiban rumah sakit dalam menjaga mutu pelayanan, kontrol infeksi, dan keselamatan pasien (Lardo, 2016).

Survei yang dilakukan (WHO, 2012) terhadap 55 rumah sakit di 14 negara menunjukkan $8,7 \%$ dari rumah sakit tersebut terdapat pasien dengan HAIs. Didapatkan 1,4 juta orang di seluruh dunia menderita infeksi akibat perawatan di rumah sakit. Frekuensi tertinggi HAIs dilaporkan oleh rumah sakit di wilayah Mediterania Timur dan Asia Tenggara berturut-turut $11,8 \%$ dan $10,0 \%$, sedangkan prevalensi di wilayah Eropa dan Pasifik Barat berturut-turut 7,7\% dan 9,0\%. Angka kejadian flebitis di Negara maju seperti Amerika terdapat angka kejadian 20.000 kematian pertahun akibat dari HAIs salah satunya adalah flebitis yang ditimbulkan oleh tindakan pemasangan terapi intravena. Sedangkan di Negara di Asia Tenggara HAIs (flebitis) sebanyak 10,0\% (Rizky, 2016).

HAIs yang ditemukan pada beberapa negara di Eropa dan Amerika berkisar kurang dari $1 \%$, sedangkan prevalensi tertinggi ditemukan pada negara di Asia, Amerika Latin, Afrika bagian Sahara sebesar 40\%.Di Indonesia HAIs mencapai $15,74 \%$ jauh di atas negaramaju yang berkisar 4,8-15,5\% (Listiowati, 2014). Di Indonesia yaitu di 10 RSU pendidikan, HAIs cukup tinggi yaitu 6$16 \%$ dengan rata-rata 9,8\% (Nugraheni, 2012). Menurut (Profil Kesehatan Provinsi Sumatera Utara, 2018) penyakit infeksi menempati urutan ke 4 kasus terbesar rawat jalan di Rumah Sakit Sumatera Utara dengan jumlah kasus 20.211 dan menempati urutan ke 4.

Menurunya standart pelayanan keperawatan menjadi salah satu faktor penyebab terjadinya HAIs. Praktik keperawatan di berbagai lingkungan pelayanan kesehatan tidak mencerminkan bentuk praktik pelayanan keperawatan yang profesional. Ada banyak alasan terjadinya HAIs, salah satunya terkait dengan proses dan sistem sanitasi, seperti perilaku profesional terkait (Listiowati, 2014).

Beberapa faktor penyebab HAIs antara lain kurangnya perhatian perawat terhadap teknik aseptik, kemampuan invasif dan kerusakan mikroba pada jaringan, usia pasien, jenis kelamin, keadaan umum pasien, risiko pengobatan atau adanya penyakit lain, dan faktor keperawatan, seperti Lamanya proses perawatan, standar pelayanan yang kurang optimal, dan kepadatan pasien di ruangan (Handojo, 2015).

Penyebab utama infeksi melalui infus (kejadian plebitis) adalah pengetahuan perawat saat melakukan pemasangan infus tidak sesuai dengan standar operasional prosedur maupun kurangnya pelaksanaan universal precaution (Haji, 2010). Perawat harus memiliki kemampuan dan pengetahuan mengenai protokol kesehatan dan implementasi untuk mencegah terjadinya komplikasi karena pengetahuan atau kognitif merupakan domain yang sangat penting dalam mambentuk tindakan seseorang. Faktor yang paling dominan ialah dari tingkat pendidikannya (Notoatmodjo, 2012). Kejadian HAIs (Flebitis) di rumah sakit pemerintah dengan jumlah pasien 1.527 pasien dari jumlah pasien beresiko 160.417 $(55,1 \%)$, sedangkan untuk rumah sakit swasta dengan jumlah pasien 991 pasien dari jumlah pasien yang beresiko $130.047 \quad(35,7 \%)$ (Zismita, 2013).

HAIs tersebut dapat dicegah dengan menerapkan tindakan pencegahan umum Penerapan tindakan pencegahan umum merupakan bagian dari pengendalian infeksi dan tidak terlepas dari peran masing-masing pihak yang terlibat yaitu pimpinan, pengelola, penyedia layanan dan pengguna layanan, termasuk pasien dan pengunjung. Tentu saja tenaga kesehatan khususnya perawat berperan penting dalam pencegahan HAIs, karena perawat merupakan salah satu anggota tim kesehatan yang bersentuhan langsung dengan pasien dan bahan infeksius di bangsal pada saat melakukan penilaian kinerja pelayanan kesehatan. perawat, salah satunya mengevaluasi aktivitas perawat dalam memberikan asuhan keperawatan sesuai dengan standar prosedur operasional dan standar keperawatan (Abdullah. K, 2012). 
Berdasarkan hasil penelitian terdahulu oleh (D., 2012) dalam penelitian yang berjudul "Hubungan Pengetahuan Perawat Tentang Infeksi Nosokomial Dengan Kejadian Plebitis DI RS Kristen Lende Moripa Sumba Barat" terdapat hubungan yang bermakna dengannilai $\rho$-value lebih kecil dari pada nilai signifikansi yaitu 0,05 yang berarti ada hubungan yang bermakna antara pengetahuan perawat tentang infeksi nosokomial dengan penerapan prinsip steril pada pemasangan infus di RS Kristen Lende Moripa, Sumba Barat dengan keeratan rendah.

Berdasarkan survey pendahuluan yang penulis lakukan di ruang interna di jumpai masih ada perawat yang belum menerapakan pencegahan infeksi seperti menggunakan alat pelindung diri penutup mulut, sarung tangan, mencuci tangan sebelum dan setelah melakukan tindakan. Berdasarkan hasil wawancara terhadap 5 perawat, terdapat 4 orang yang tidak bisa menjelaskan faktor yang mempengaruhi terjadinya HAIs meliputi penyebab terjadinya HAIs, faktor resiko, pengendalian dan pencegahan HAIs dari hasil observasi peneliti menemukan masih ada perawat yang melakukan pemasangan infus tanpa memperhatikan kesterilannya dan tidak sesuai dengan SOP, nierbeken yang di letakan tidak sesuai, tempat kapas alkohol bercampur dengan benda lain, pada saat melakukan tindakan pemasangan infus masih ada perawat yang tidak melakukan cuci tangan setelah melakukan tindakan, perawat juga tidak membereskan alat ke tempatnya.

Berdasarkan permasalahan diatas maka peneliti tertarik untuk meneliti tentang apakah ada hubungan pengetahuan perawat tentang health associated infections (hais) dengan penerapan prinsip steril pemasangan infuse di Rumah Sakit Umum Daerah H. Sahudin Kutacane Kabupaten Aceh Tenggara.

\section{METODE}

Jenis penelitian ini menggunakan studi deskriptif korelasi dengan rancangan penelitian cross sectional yang bertujuan untuk mengetahui hubungan pengetahuan perawat tentang Health Associated Infections (HAIs) dengan penerapan prinsip steril pemasangan infus di Rumah Sakit Umum Daerah H. Sahudin Kutacane Kabupaten
Aceh Tenggara. Penelitian ini dilaksanakan di Rumah Sakit Umum Daerah H. Sahudin Kutacane Kabupaten Aceh Tenggara.

Populasi pada penelitian ini adalah seluruh perawat pelaksana yang bekerja di Rumah Sakit Umum Daerah H. Sahudin Kutacane Kabupaten Aceh Tenggara berjumlah 332 orang. Besar sampel penelitian ini ditentukan dengan rumus $\mathrm{n}=10 \% \times \mathrm{N}$, Jadi besar sampel dalam peneltian ini adalah sebanyak 33 responden yang diambil dengan menggunakan teknik accidental sampling yaitu perawat yang kebetulan melakukan pemasangan infus. Teknik pengolahan data pada penelitian ini melalui proses editting, coding, entri data, dan tabulating. Analisa pada penelitian ini meliputi analisa univariat dan analisa bivariat.

\section{HASIL DAN PEMBAHASAN \\ 3.1 Hasil \\ Analisa Univariat \\ 1. Karakteristik Responden}

Tabel 1. Distribusi Frekuensi Data

Demografi BerdasarkanUmur, Jenis Kelamin Responden di Rumah Sakit Umum Daerah H. Sahudin Kutacane Kabupaten Aceh Tenggara

\begin{tabular}{lcc}
\hline Karakteristik Responden & F & \% \\
\hline Umur & & \\
\hline $25-40$ & 23 & 69,7 \\
\hline $41-55$ & 10 & 30,3 \\
\hline Jenis Kelamin & & \\
\hline Laki-laki & 10 & 30,3 \\
\hline Perempuan & 23 & 69,7 \\
\hline Pendidikan & & \\
\hline D3 & 19 & 57,6 \\
\hline S1 & 14 & 42,2 \\
\hline Lama bekerja & & \\
\hline$<5$ tahun & 18 & 54,5 \\
\hline$>5$ & 15 & 45,5 \\
\hline Kepegawaian & & \\
\hline PNS & 16 & 48,5 \\
\hline Non PNS & 17 & 51,5 \\
\hline Status Pernikahan & & \\
\hline Menikah & 21 & 48,5 \\
\hline Belum menikah & 12 & 51,5 \\
\hline Pelatihan & & \\
\hline Tidak pernah & 20 & 60,6 \\
\hline Pernah & 13 & 39,4 \\
\hline \multicolumn{1}{l}{ Berdarkan } &
\end{tabular}

Berdasarkan tabel 1 dapat dilihat umur responden mayoritas yaitu 25-40 tahun $69,7 \%$, jenis kelamin perempuan lebih mayoritas yaitu $69,7 \%$, pendidikan D3 mayoritas yaitu $57,6 \%$, lama bekerja mayoritas 1-5 tahun yaitu 54,5\%, 
kepegawaian mayoritas non PNS yaitu $51,5 \%$, status pernikahan mayoritas menikah yaitu $63,6 \%$, pelatihan mayoritas tidak pernah yaitu $60,6 \%$.

Tabel 2. Distribusi Frekuensi Pengetahuan Perawat Tentang Health Associated Infections (HAIs) Rumah Sakit Umum Daerah H. Sahudin Kutacane Kabupaten Aceh Tenggara

\begin{tabular}{lcc}
\hline \multicolumn{1}{c}{ Pengetahuan } & F & \% \\
\hline Baik & 0 & 0 \\
\hline Cukup & 30 & 90,9 \\
\hline Kurang & 3 & 9,1 \\
\hline \multicolumn{1}{c}{ Total } & $\mathbf{3 3}$ & $\mathbf{1 0 0}$ \\
\hline
\end{tabular}

Berdasarkan tabel 2 dapat dilihat bahwa pengetahuan perawat tentang HAIs Rumah
Sakit Umum Daerah H. Sahudin Kutacane adalah cukup dengan hasil 90,9\%.

Tabel 3. Distribusi Frekuensi Penerapan Prinsip Steril Pemasangan Infus Di Rumah Sakit Umum Daerah H. Sahudin Kutacane Kabupaten Aceh Tenggara

\begin{tabular}{cccc}
\hline \multicolumn{2}{l}{ Penerapan Prinsip Steril } & F & \% \\
\hline Baik & 21 & 63,6 \\
\hline Buruk & 12 & 36,4 \\
\hline \multicolumn{2}{c}{ Total } & $\mathbf{3 3}$ & $\mathbf{1 0 0}$ \\
\hline
\end{tabular}

Berdasarkan tabel 3 dapat dilihat bahwa penerapan prinsip steril Pemasangan Infus Di Rumah Sakit Umum Daerah H. Sahudin Kutacane adalah baik dengan hasil 63,6\%.

\section{Analisa Bivariat}

Tabel 4. Tabulasi Silang Hubungan Pengetahuan Perawat Tentang Tentang Health Associated Infections (HAIs) Dengan Penerapan Prinsip Steril Pemasangan Infus di Rumah Sakit Umum Daerah H. Sahudin Kutacane Kabupaten Aceh Tenggara

\begin{tabular}{|c|c|c|c|c|c|c|c|}
\hline \multirow{3}{*}{ Pengetahuan } & \multicolumn{4}{|c|}{ Prinsip Steril } & \multirow[t]{3}{*}{ f } & \multirow[t]{3}{*}{$\%$} & \multirow[t]{3}{*}{ P Value } \\
\hline & \multicolumn{2}{|c|}{ Baik } & \multicolumn{2}{|c|}{ Buruk } & & & \\
\hline & $\mathbf{f}$ & $\%$ & f & $\%$ & & & \\
\hline Cukup & 21 & 63,6 & 9 & 27,3 & 30 & 90,9 & 0,016 \\
\hline Kurang & 0 & 0 & 3 & 9.1 & 3 & 9,1 & \\
\hline
\end{tabular}

Berdasarkan tabel 4 dapat dilihat bahwa Kabupaten Aceh Tenggara mayoritas baik. dari pengetahuan perawat yang cukup tentang HAIs sebanyak $90,9 \%$, penerapan prinsip steril baik sebanyak $63,6 \%$, dan penerapan prinsip steril buruk sebanyak 27,3\%, sedangkan dari pengetahuan perawat kurang tentang HAIs sebanyak 9,1\%, dengan penerapan prinsip steril buruk. Dengan hasil $\mathrm{p}$ value $0,016(\mathrm{p}=<0,05)$ yang menunjukkan bahwa ada hubungan pengetahuan perawat dengan HAIs.

\subsection{Pembahasan}

\section{a. Pengetahuan Perawat Tentang Health Associated Infections (HAIs)}

Menurut asumsi peneliti bahwa mayoritas pengetahuan perawat tentang Health Associated Infections (HAIs) memilki tingkat pengetahuan yang cukup baik di karena semakin lama masa kerja dan tingkat pendidikan perawat semakin baik pula pengetahuan perawat.

\section{b. Penerapan Prinsip Steril Pemasangan Infus}

Menurut asumsi peneliti penerapan prinsip steril pemasangan infus di Rumah Sakit Umum Daerah H. Sahudin Kutacane Ada beberapa faktor yang mempengaruhi hal tersebut seperti tingkat pendidikan dan lamanya masa kerja, fasilitas dan sarana juga termasuk hal yang mempengarahi penerapan prinsip steril oleh perawat.

c. Hubungan Pengetahuan Perawat Tentang Health Associated Infections (HAIs) Dengan Penerapan Prinsip Steril Pemasangan Infus

Menurut asumsi peneliti bahwa hubungan pengetahuan perawat tentang Health Associated Infections (HAIs) dengan penerapan prinsip steril pemasangan infus di Rumah Sakit Umum Daerah H. Sahudin Kutacane Kabupaten Aceh Tenggara mayoritas cukup.

\section{KESIMPULAN}

Dari hasil penelitian diatas dapat disimpulkan bahwa:

1. Pengetahuan perawat tentang Health Associated Infections (HAIs) di Rumah Sakit Umum Daerah H. Sahudin Kutacane Kabupaten Aceh Tenggara Tahun 2019 mayoritas cukup. 
2. Penerapan prinsip steril pemasangan infus di Rumah Sakit Umum Daerah $\mathrm{H}$. Sahudin Kutacane Kabupaten Aceh Tenggara Tahun 2019 mayoritas baik.

3. Ada hubungan yang signifikan antara hubungan pengetahuan perawat tentang Health Associated Infections (HAIs) dengan penerapan prinsip steril pemasangan infus di Rumah Sakit Umum Daerah H. Sahudin Kutacane Kabupaten Aceh Tenggara Tahun 2019.

\section{REFERENCES}

Abdullah. K. (2012). Hubungan Pengetahuan, Motivasi, dan Supervisi dengan Kinerja Pencegahan Infeksi Nosokomial di RSUD H Makassar. 1-2.

D., M. D. M. (2012). Hubungan Pengetahuan Perawat Tentang Infeksi Nosokomial Dengan Kejadian Plebitis DI RS Kristen Lende Moripa Sumba Barat.

Profil Kesehatan Provinsi Sumatera Utara, (2018).

Haji, B. S. (2010). Hubungan Tingkat Kompetensi Pada Aspek Ketrampilan Pemasangan Infus Dengan Angka Kejadian Plebitis Di RSUD Banyudono Kabupaten.

Handojo. (2015). Pengetahuan Perawat tentang Infeksi Nosokomial di Ruang D2 san D3 di RS H Husada Undaan Wettan
Surabaya. 1.

Kemenkes RI. (2017). Program Pencegahan dan Pengendalian Infeksi Nosokomial Merupakan Unsur Patient Safety. Kementrian Kesehatan Republik Indonesia.

Lardo, S. (2016). Infection Control Risk Assesment (ICCRA). Ar-Ruzz Media.

Listiowati, E. (2014). Hubungan Tingkat Pengetahuan Hand Hygiene dengan Kepatuhan Pelaksanaan Hand Hygiene Pada Peserta Program Pendidikan Profesi Dokter.

Notoatmodjo. (2012). Ilmu Perilaku Kesehatan. Rineka Cipta.

Nugraheni, R. (2012). Pengetahuan Perawat Tentang Infeksi Nosokomial.

Rizky, W. (2016). Analisa Faktor yang Berhubungan Dengan Kejadian Flebitis Pada Pasien Yang Terpasang Intravena Di Ruang Bedah Rumah Sakit Ar. Bunda.

WHO. (2012). Prevention of hospitalacquired infections, A practical guide 2nd edition.

Zismita, L. R. . (2013). Hubungan Tingkat Pengetahuan Perawat Tentang Infeksi Nosokomial Dengan Angka Kejadian Plebitis Di Rumah Sakit Umum Daerah Kota Yogyakarta. 